\title{
Is E-Learning replacing the traditional Lecture?
}

\author{
Jonathan D Owens and Liz Price \\ Lincoln Business School, University of Lincoln, Lincoln, UK.
}

\begin{abstract}
Purpose - The purpose of this paper is to review some of the learning technologies associated with teaching and learning in Higher Education (HE). It looks at Elearning and Information Technology (IT) as tools for replacing the traditional learning experience in HE, i.e. the 'chalk and talk' lecture and seminar. HE is on the threshold of being transformed through the application of learning technologies. Are we on the brink of a new way of learning in HE after a tried and tested formula over eight hundred years?

Design/methodology/approach - Adopting a case based approach, the fieldwork for this research took place at two UK Higher Education Institutes (HEI's). A number of units that included IT based learning were identified. All units included a web site that was aimed at supporting students' learning. The data was collected through unstructured discussion with the lecturer and a questionnaire to students.

Findings - This paper considers and highlights the key findings from the sample linking them to the literature with the purpose of testing the aim/title of this paper. Evidence suggested the implications for HEI's are they cannot assume that presenting new technologies automatically makes their institutions "youth friendly"; this new generation would like to see some concrete benefits of technology.

Originality/value - From this small-scale investigation this paper attempts to investigate which direction the threshold may go. There has been eight hundred years of learning in the UK, is this generation wanting a new chapter. Evidence from this research suggests not, it will only play a bit part. They can help free up time in order to engage and support students in new and interesting ways.
\end{abstract}

Key Words - E-learning, Learning Technologies, Information Technology (IT), Teaching and Learning in Higher Education, Distance Learning.

Paper type - Research paper 


\section{Introduction}

"If we forget the eight hundred years of university tradition that legitimises them, and imagine starting afresh with the problem of how best to enable a large percentage of the population to understand difficult and complex ideas, I doubt that lectures will immediately spring to mind as the obvious solution.” (Laurillard, 2005)

Various authors (Kalkota \& Whinston, 1996; Turban et al, 2000; Owens, 2002; Owens and Floyd, 2007) have identified that the Internet offers unique opportunities in both teaching and learning applications. A common theme that appears to have changed little (Ackoff, 1989; Dearing, 1997; Conaway et al, 2005; Falconer, 2006) is that students are very keen on using the Internet for entertainment, peer communication, and for secondary sources of data. Researchers (Lissenburgh, 1999; Hamilton and Scandura, 2003; Macfayden, 2005) claim that, in some cases, students assume the information does not exist if it is not available on the Internet.

Although students are familiar with Internet technology, some researchers (Gladstone, 2000; Wang and Ahmed, 2003; Hannon and D’Netto, 2007) argue that students often lack the specific skills that would enable them to use it more effectively. It could be that students are not clear of the benefits from the outset (Ashraf, 2009). A recent survey (Student Expectations Study, 2007) reported that, whilst many current and prospective students are comfortable with the learning technologies both used and available, this new generation of students like to see the concrete benefits of technology usage and implementation, i.e. that work is recognised and contributes to final grade assessment.

This paper will review e-learning and IT as learning technologies in order to evaluate if they can be used to replace the traditional style lecture.

\section{Evidence of Internet use}

According to the 2005 Oxford Internet survey ninety two percent of people go on line to check emails, seventy four percent buy on line and forty three percent play games, forty two percent look for jobs. However, only twenty one percent use it for distance 
learning purposes. Even use of the internet to download to watch videos and listen to the radio achieved an almost ten percent better score than distance learning. It is also evident that there has been a decline in the number of people developing websites, and using the Internet for creative purposes. Another finding which is disappointing for learning purposes is that twenty percent read less due to the advent of the Internet. This suggests the internet is not a perfect substitute for knowledge, and that lecturers need to encourage both means to foster more creativity. A summary of the twenty main reasons people access the internet is illustrated in table 1.

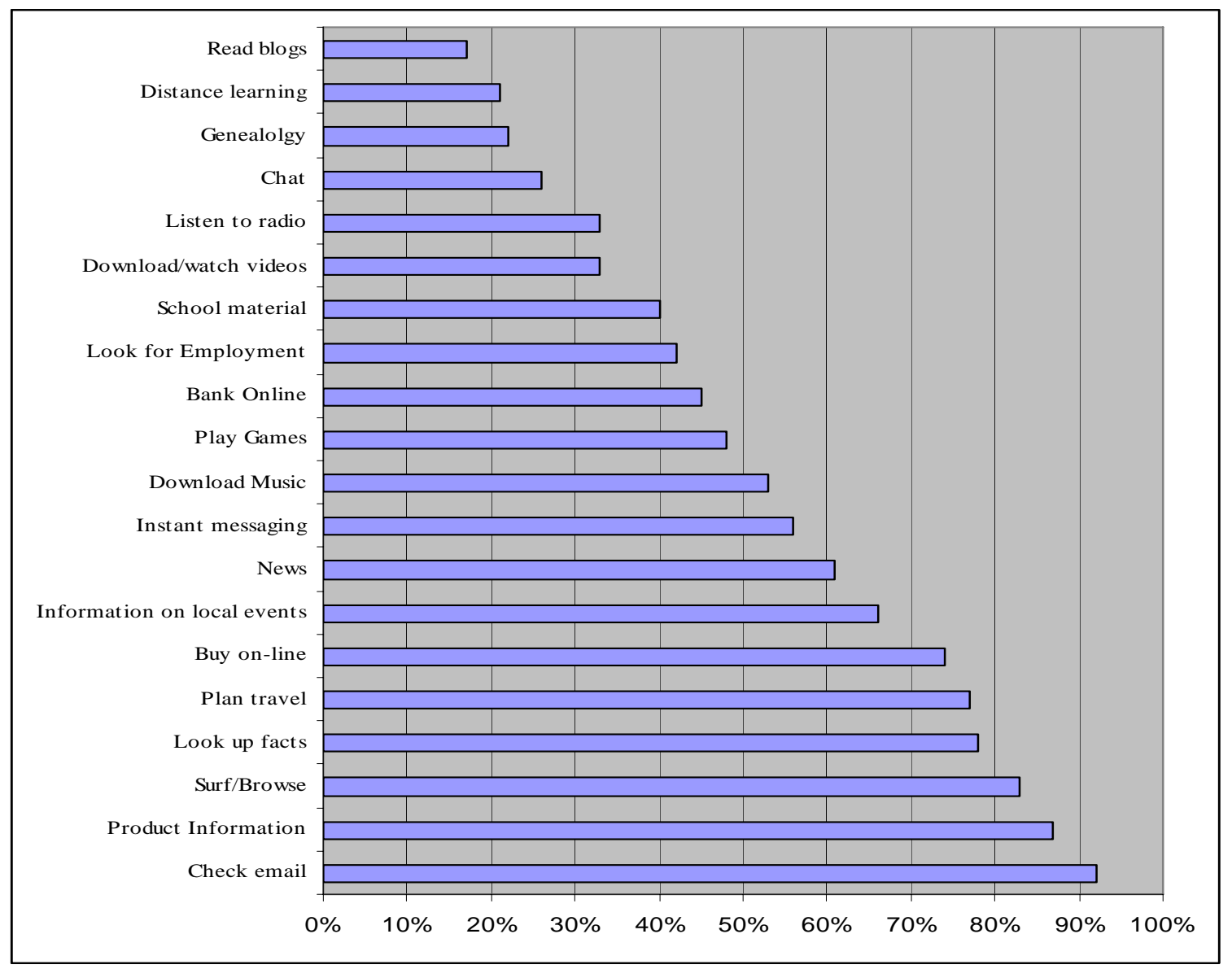

Table 1. Twenty fundamental reasons why we go online (Oxford Internet Survey, 2005)

\section{Knowledge Transfer using E-Learning and Learning Technologies in HE}

Research indicates (Hannon and D’Netto, 2007; Owens, 2002, 2006; Macfayden, 2005; Wang and Ahmed, 2003) that E-Learning is perceived as a key enabler to Knowledge Transfer (KT) within the HE sector. E-learning can be used to facilitate 
$\mathrm{KT}$ in a number of ways, as set out in Figure 1. The successful introduction and implementation of e-Learning into existing and new units at Higher Education Institutes (HEI's) is heavily influenced by the institution's ability to deliver knowledge based products. Also research indicates (Conaway et al, 2005; Goodfellow and Lea, 2007) HEI's need to be effective at managing any number of strategic issues that may arise as part of the development of KT though e-Learning products.

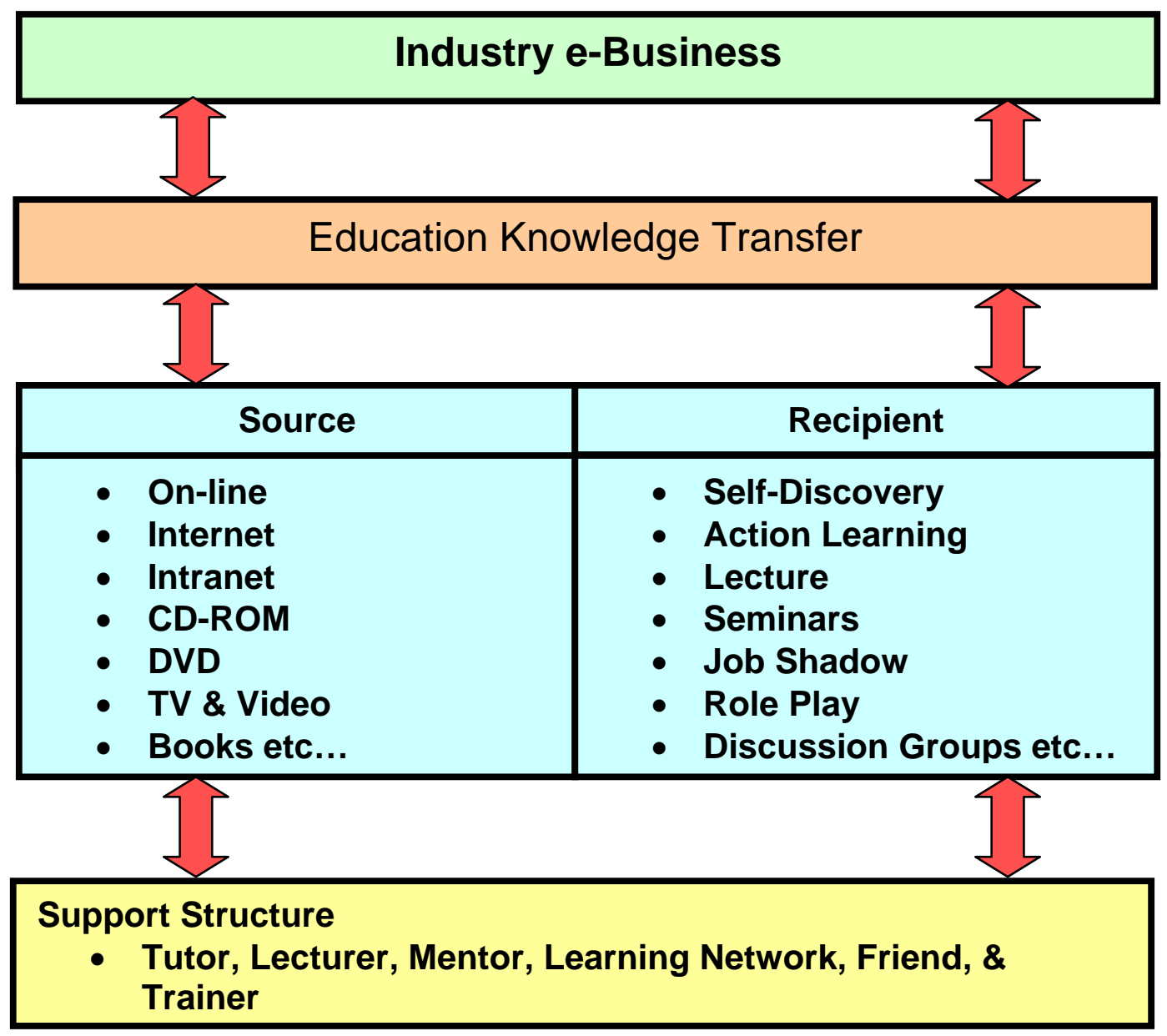

Figure 1 Model of Knowledge Transfer Education to Business (Owens and McManus, 2004)

The most significant strategic issues (Conaway et al, 2005) to consider when implementing e-Learning as a tool for KT through traditional and independent study within the HE sector are:

- Identifying the customer service imperative for each stakeholder or institute involved in an e-Learning initiative. 
- Appreciating the advantages and disadvantages of incremental KT through eLearning in HE.

- Understanding the value of national, integrated approaches to e-Learning and $\mathrm{KT}$ in HE.

- Understanding the need to develop user support systems, to underpin eLearning and KT developments.

- Working within technological and financial limitations associated with HEI's

- Successful internationalisation of University Education.

Developing KT schemes with the aid of e-Learning is expensive both in time and money (Owens and McManus, 2004). Consequently, before making the investment, HEI's may prefer to establish if it is worthwhile (Goodfellow, 2005). It may therefore be beneficial to have a strategy in place for sustaining and embedding the institutes proposed KT and e-Learning developments. Owens and McManus (2004) suggest there are two schools of thought when considering the integration of $\mathrm{KT}$ and eLearning.

1. The exploration of technologies currently known and understood to produce sound learning and teaching KT through the model (see figure 1). Where the current technologies available in the HEI do not allow this, then both internal and external developers should be encouraged to assess if new technologies are necessary, in order to provide a feasible solution for all parties involved in the KT process.

2. To examine the current technologies within the HEI and explore the possibilities for innovation that can lead to the development of new pedagogies and enhance the KT process in the model. This school of thought believes that the potential of the technology that currently exists has not yet been fully investigated. Thus, it focuses on the premise of embedding new practices before moving onto new technologies to assist the KT process.

\section{Learning Technologies}

Research (Gladstone, 2000; Reeder et al, 2004; Weller, 2004) suggests that academics have accepted the idea that Information Technology (IT) can be effectively used for 
teaching and learning. According to Roberts (2004), students increasingly expect the presence and use of IT in Higher Education (HE). In some environments the high penetration of IT has become the norm or at least one of the indicators of the quality of a university or faculty (Lanham and Zhou, 2003). Alexander (2002) claims new students expect the institutions to offer up-to-date IT and Internet access. Further studies suggest (Goodfellow, 2004; Goodfellow and Lea, 2007) that some institutions are using IT as a competitive advantage in order to attract more students in an increasingly competitive HE market. More and more, students expect lecturers to use IT for teaching and learning (Goodyear and Jones, 2003). This is particularly true for mature and distance learning students who are often in full-time employment and from a working environment, where IT is a fundamental tool (Lanham and Zhou, 2003).

\section{An Evaluation of some of the Learning Technologies available}

Learning technology can effectively assist teaching when it is seen as one of a set of activities aimed at supporting students' learning (Akgun et al, 2003; Boyce, 2003; Chou, 2003). This approach corresponds to the level three of Biggs' student-centred theory about teaching (Biggs, 1999). Here, student learning depends on the student's ability, prior knowledge and accessible new knowledge on the academic subject/field, including teacher responsibility, decision-making and good management. Therefore, good teaching, including the use of learning technologies, involves an awareness of contextual dependency of learning and teaching (Borstorff and Lowe, 2007; Falconer, 2006; Goodfellow, 2005; Gosper et al, 2008).

The evaluation of learning technologies includes examining the intentions, implementation process and the outcomes of technology use (Hannon and D'Netto, 2007). According to Jackson (1998) and Sims and Jones (2002) the purpose of evaluating learning technologies is to provide the designer or user with enough evidence on which to make confident judgements regarding the effectiveness of the innovation. He also claims that the match between the intentions and outcomes determines the success; therefore it is important that the intentions add value to student learning. According to Elkin (2005) success can also lead to further expansion 
into the international education market where specialist focus on Europe should lead to a niche market for UK and EU Higher Education providers.

Existing research suggests (Jackson, 1998; Gladstone, 2000; Falconer, 2006, Goodfellow, 2007; Gosper et al, 2008) learning technologies can be evaluated against intended outcomes such as ease of use, efficiency, student preferences, technology attractiveness, and cost effectiveness.

\section{Using IT for teaching and Learning}

Borstorff and Lowe (2006) claim the introduction of IT represents an additional burden on lecturers' timetables, as it requires co-ordination and integration of the activities in the teaching programme. In order to be effective, IT must reflect the current constructivist-learning model that over the last few decades evolved from behaviourist and objectivist models (Fry et al, 1999; Borstorff and Lowe, 2007). Above all, IT-enabled learning must foster interaction and dialogue between the learner(s) and the teacher (Goodfellow, 2005). Research (Institute of Teaching and Learning Seminar, 2003; Roberts, 2004; Goodfellow and Lea, 2007) suggests that learning using IT can be enhanced in all sorts of ways, including hearing, seeing, as well as participating in activities such as a game or quiz.

Hannon and D'Netto (2007) argue that the potential of learning technologies to improve learning depends on the context of learning and assessment. The context is defined by the combination of its elements that include the students, lecturers, institution, teaching material, style and method. Research by Ashraf (2009), Goodfellow (2007) and Gosper et al (2008) claim the majority of studies in this area fail to provide solid evidence of increased effectiveness of the IT for teaching and learning. As discussed earlier (Student Expectations Study, 2007), when considering technology, there should perhaps be a manner of caution in adoption and utilisation. This is because HEI's cannot assume that presenting new technologies automatically makes their institutions "youth friendly", this new generation would like to see some concrete benefits of technology. Additionally, Gosper et al (2008) report that IT for teaching and learning contributes to a "blurring" of the boundaries between traditional (full-time) and non-traditional (part time, distance learning) students. This 
is primarily because its introduction is more than solely a teaching issue as it can affect the design of the unit and programme, as well as having professional and organisational development implications.

The literature indicates that students are enthusiastic (Jackson, 1998; Roberts, 2004) about the IT, and they take the medium more seriously when their work is assessed (Fry et al, 1999; Borstorff and Lowe, 2004). However, both Hannon and D’Netto (2007) and Goodfellow (2007) state IT fails to enable the achievement of significantly different learning outcomes. They also suggest that organisational and logistical problems combined with technical difficulties mean that the IT cannot always be used to its full potential. In order to work more effectively, learning technologies must be fully embedded in a course and students must be provided with the adequate skills and support (Falconer, 2006; Turban et al, 2000).

\section{Methodology}

The fieldwork for this research took place at two UK HEI's; Lincoln Business School (LBS), University of Lincoln and Buckinghamshire Business School (BBS), Buckinghamshire New University. A number of units that included IT-based learning were identified at both HEI's.

Three units that offered similar content and level were selected for this study. All the units include a web site aimed at supporting students' learning. The site gives the lecturer some degree of flexibility in terms of inclusion of teaching material, and setting up the discussions despite being fairly standardised. The cohort for this study includes both undergraduate and postgraduate students studying fulltime at both HEI’s.

The fieldwork included an unstructured interview/discussion with the lecturer for each cohort and a questionnaire for the students. The discussion with the lecturer aimed to identify the main issues related to use of the web site that emerged during the semester. The issues identified through this discussion formed the basis for the 
questionnaire distributed to the students towards the end of the semester. The breakdown of respondents for each module and HEI is illustrated in table 2.

\begin{tabular}{|c|c|c|c|c|c|}
\hline \multicolumn{3}{|c|}{ Lincoln Business School } & \multicolumn{3}{|c|}{ Buckinghamshire Business School } \\
\hline Module & Level & $\begin{array}{l}\text { Number of } \\
\text { Respondents }\end{array}$ & Module & Level & $\begin{array}{l}\text { Number of } \\
\text { Respondents }\end{array}$ \\
\hline $\begin{array}{l}\text { Operations } \\
\text { Management }\end{array}$ & CMS & 17 & $\begin{array}{l}\text { Operations } \\
\text { Management }\end{array}$ & CMS & 12 \\
\hline $\begin{array}{l}\text { Strategic } \\
\text { Management }\end{array}$ & BA 3 & 14 & $\begin{array}{l}\text { Strategic } \\
\text { Management }\end{array}$ & BA 3 & 17 \\
\hline \multirow[t]{3}{*}{$\begin{array}{l}\text { Management } \\
\text { of Operations }\end{array}$} & BA 2 & 19 & $\begin{array}{l}\text { Management } \\
\text { of Operations }\end{array}$ & BA 2 & 13 \\
\hline & Total & 50 & & Total & 42 \\
\hline & & $\begin{array}{r}\text { Overall } \\
\text { Total }\end{array}$ & 92 & & \\
\hline
\end{tabular}

Table 2 Respondents breakdown from both HEI's.

\section{Findings}

The following is a discussion of the outcomes from the primary data collection at the two cases.

\subsection{Interview}

From the interview with the lecturer it emerged that the teaching team for each unit provided a web site that aimed to offer additional support for the students. Although standardised to some extent, the web site offers a certain degree of flexibility. The lecturer was able to publish the lecture notes, the syllabus, the module outline, the assessment brief and any other text material. The related web links could be edited at the discretion of the lecturer who has the control over the content of the web site. Additionally, the lecturer could set up a discussion area by proposing a topic and encouraging student participation. Typically, the lecturer posted a question related to the lecture on a weekly basis. The students could respond or comment on the topic and get the lecturer's feedback. The students could see the contributions of their fellow students but could not address the comment to one particular student. Similar to research by Chou (2003), the communication channel corresponded to the 
interactive of one-to-many model. Each participant was identified through a username and a password.

The discussion with the lecturer allowed for identification of main themes and items that were then included in the questionnaire. For example, ascertaining how often the student accessed the discussion area, if they found it helpful, and if they contributed. The feedback helped to build a picture of the level of interaction between the student and the lecturer using internet-based learning. Once the questionnaire had been drafted, it was reviewed by the lecturer, and the final version administered to students during one of the last sessions in semester one. This is similar to Goodfellow's (2007) thoughts on encouraging links between the two parties involved in the learning process.

\section{Questionnaires}

The following results combine the findings from both LBS and BBS across all levels investigated.

\section{Feedback from Certificate in Management Studies (CMS) for the Operations Management module at LBS and BBS.}

These students scored the lowest usage rate of the three groups involved in this research. Only twenty one percent of respondents at LBS and nineteen percent of respondents at BBS log on to the web site at least once a week. Approximately two thirds of the students at the two institutes visit the web site once per month or less, or not more than five times in a semester.

When the students log on they mostly look at the lecturer's questions but only one in four contributes to the discussion. Across both institutes approximately two thirds look at the contributions of other students and use the web links. Less than half use the web based lecture notes and less than a third use other material related to the assessment. This finding is not surprising as it supports the common view (Fry et al, 1999; Borstorff and Lowe, 2007), that the student will only take this medium of study more seriously if it is assessed. Hannon and D’Netto (2007) comment that the real 
potential of learning technologies to improve the student's learning experience depends upon the context of learning and assessment.

At both institutes, the majority of students feel the web site helps their learning, makes it easier to keep up to date with the lectures, offers the opportunity to discuss questions with the lecturer, and ask for clarifications. The use of the website therefore promotes efficiency, effectiveness, ease of use and attractiveness as a mode of learning (Jackson, 1998; Gladstone, 2000; Falconer, 2006, Goodfellow, 2007).

However, a large majority of students at both institutes do not think the web site gives the lecturer a tool to monitor their learning, nor themselves the opportunity to show how much they study. This is supported by both Goodfellow (2005) and Ashraf (2009), who identified this to be a particular constraint. They suggest more development needs to be undertaken with this mode of learning in order to achieve its full potential for both lecturers and students. The implications for students who are technically competent is that the use of web-based interaction may deliver 'concrete' benefits which involves measuring their level of understanding and improvement.

Another common finding from both institutes was that the vast majority would like the web site to contain more assessment/learning-related material. There were differing views on whether web-based activities should be included as part of a broad portfolio of activities, or be subject to formal assessment. Approximately half the students welcome the inclusion of web-based work as part of a broad portfolio, where the work is assessed solely on a pass/fail basis. However, less than a third would like web-based activities to be formally assessed and included as part of the final grade. This is similar to findings from Hannon and D'Netto (2007), who suggest this mode of learning should be part of the student's assessment. Finally, approximately half of the respondents would like the web site to be more enjoyable to use. 


\section{Feedback from the BA 3 Strategic Management module at LBS and BBS.}

Almost two thirds of the students at each institute visit the web site at least every other week. They predominantly use the lecture notes, look at the lecturer's questions, and at the contributions from other students. However, only seventeen percent at LBS and fourteen percent at BBS have ever contributed to the discussion on the web site.

Similar to earlier findings with the CMS cohort, the students at both institutes felt that the web site helps their learning; makes it easier to keep up to date with the lectures, offers the opportunity to discuss questions with the lecturer, and to ask for clarifications. Approximately one in four at LBS and one in three at BBS agree that it should be part of the portfolio of activities. However, an interesting finding was that the majority of students studying this module at both institutes agreed that web-based work should not be formally assessed for this module at this level of study. This did not follow earlier trends in this research, nor the literature (Hannon and D'Netto, 2007), where students would prefer to see it as part of their assessment. A possible explanation for this could be that, as this group comprised level three students, they were more aware of the significance of grade at this stage of their degree programme. They perhaps preferred the familiarity and 'concrete benefits' (Student Expectations Study, 2007) of the traditional assessment methods.

The vast majority of students at both institutes were of the opinion that they would use it more often if there was more material related to the module assessment. This finding is similar to previous research (Falconer, 2006, Goodfellow, 2007) whereby relevance to the course and supporting the teaching curriculum.

\section{Feedback from the BA 2 Management of Operations module at LBS and BBS.}

It was both an interesting and common finding at both institutes that almost half (forty nine percent LBS and forty seven percent BBS) of the students use the web site on a weekly basis. This was perhaps an expected finding at level three undergraduate, rather than level two undergraduate because of the maturity of the student towards 
learning and, the weighting of the degree programme at the final level in England and Wales.

Similar to the previous two cohorts, these students mostly use the lecture notes; they look at the lecturer's questions and use the web links. Across both institutes, approximately half the respondents think the web site helps their learning and that it makes it easier to keep up to date with the lectures. This is a finding supported by Goodyear and Jones (2003), who identify that there is a clear expectation by students to use IT for teaching and learning. One in three at LBS and one in four at BBS thought that it offered them the opportunity to have discussions with the lecturer, ask questions, to show how much they study, and that it should be part of the portfolio. However, only one in four at both institutes thought it should be assessed.

The students at both institutes were of the opinion they would use the web site more often if it counted towards the final mark, if there was additional learning material and if there was more material related to the assessment. Another common finding was that the lecturer should promote the web site more convincingly during the lectures and seminars. It should also be easier to use and it should be part of the portfolio of activities.

\section{Findings}

The key findings from the survey of students are summarised in Table 3. The ticks indicate where more than half the cohort had used the particular function of the website, or had expressed a preference for how the website had been used. 


\begin{tabular}{|l|c|c|c|c|c|c|}
\hline & \multicolumn{3}{|c|}{ LBS } & \multicolumn{3}{c|}{ BBS } \\
\hline Use of Unit Web Site: & CMS & BA3 & BA2 & CMS & BA3 & BA 2 \\
\hline To log on/visit regularly & X & $\checkmark$ & $\checkmark$ & X & $\checkmark$ & $\checkmark$ \\
\hline To look at the lecturer's questions & $\checkmark$ & $\checkmark$ & $\checkmark$ & $\checkmark$ & $\checkmark$ & $\checkmark$ \\
\hline To contribute to the discussion & X & X & $\checkmark$ & X & X & $\checkmark$ \\
\hline To look at lecture notes & $X$ & $\checkmark$ & $\checkmark$ & $X$ & $\checkmark$ & $\checkmark$ \\
\hline To look at web links & $\checkmark$ & $\checkmark$ & $\checkmark$ & $\checkmark$ & $\checkmark$ & $\checkmark$ \\
\hline To interact with the lecturer & $\checkmark$ & $X$ & $\checkmark$ & $\checkmark$ & X & $\checkmark$ \\
\hline To interact with other students & $\checkmark$ & $X$ & $\checkmark$ & $\checkmark$ & X & $\checkmark$ \\
\hline To look at material related to assessment & $\checkmark$ & $\checkmark$ & $\checkmark$ & $\checkmark$ & $\checkmark$ & $\checkmark$ \\
\hline & & & & & & \\
\hline How effective is the Web Site for & & & & & & \\
\hline Monitoring learning? & $X$ & $\checkmark$ & $\checkmark$ & $X$ & $\checkmark$ & $\checkmark$ \\
\hline Demonstrating how much students study? & $X$ & & & $X$ & & \\
\hline & & & & & & \\
\hline Should the Web-based activities: & & & & & & \\
\hline Form part of a portfolio of work? & $\checkmark$ & $X$ & $\checkmark$ & $\checkmark$ & $X$ & $\checkmark$ \\
\hline Form part of formal assessment? & $X$ & $X$ & $X$ & $X$ & $X$ & $X$ \\
\hline & & & & & & \\
\hline
\end{tabular}

Table 3 Thematic Summary of Responses for each Cohort

The majority of respondents across both institutes would like to see more teaching material and more material related to their assessment presented on the unit web site. A common theme similar to Hannon and D'Netto's (2007) findings is that they would use the web site more often if it counted towards their final mark. Assessment could consist of a small component of the unit's total marks. For example, there were positive aspects for including the web-based work in the portfolio of activities, and a small minority of students supported making it count toward their final mark. However, students said they would be more likely to undertake work that they would be rewarded for, which suggests that some kind of assessment of web-based activity could promote use of e-learning. Macfayden (2005) claims that this is part of human nature and that the students will not do anything unless they clearly benefit through a contribution to their grade.

Education is on the threshold of being transformed through the application, integration and utilisation of learning technologies in UK HEI's. However, it has been on the threshold for some time now (Laurillard, 2008). Personalisation, flexibility of delivery and inclusion of a wider participation are cited (Laurillard, 
2008) as being key ambitions for learning technologies in education. However, perhaps we should not fully enter the route of making HE "techno friendly" institutes, because as discussed the current generation want to see the concrete benefits (Student Expectations Study, 2007) of “click and mortar” (Ashraf, 2009) learning before they sign up. The contributions of Internet learning should therefore count towards the completion of only part of the module (Goodfellow, 2005).

\section{Conclusion}

An encouraging thought (from a traditional perspective) is that, for now, it appears this mode of learning will act only in a supportive capacity to the traditional teaching and learning approach at HEI's. So, in an attempt to address the question, “Is ELearning replacing the traditional Lecture?" the indication from this research is not at the moment. From a wider perspective it is impossible to say but it may not be as far away as we think. Ashraf (2009) claims that, by the end of 2010, more than fifty percent of all courses offered will be a hybrid of face-to-face and online learning and more than eighty percent of students will use mobile technology as a tool for learning.

\section{References}

- Ackoff, R L (1989). From Data to wisdom. Journal of Applied Systems Analysis, Vol. 16, Issue 2.

- Akgun, A E, Lynn, g S and Byrne, C (2003). Organisational learning: a socio-cognitive framework. Human Relations, vol. 56, no. 7, pp 839-868.

- Alexander, S (2002). Designing learning activities for an international on line student body: what have we learned?" Journal of Studies in International Education, vol. 6, no. 2, pp 188-200.

- Ashraf, B (2009). Teaching the Google-eyed YouTube generation. Education and Training Journal, vol. 51, no. 5/6, pp 343-352.

- Biggs, J. (1999). "Teaching for quality learning at University." Buckingham: Open University Press.

- Borstorff, P C and Lowe, K S (2006). E-Learning: Attitudes and Behaviours of End-Users. Proceedings of the Academy of educational Leadership, vol. 11, no. 2, pp 45-49.

- Borstorff, P C and Lowe, K S (2007). Student Perceptions and opinions toward E-Learning in the College Environment. Academy of Educational leadership Journal, vol. 11, no. 2, pp 13-29. 
- Boyce, M E (2003). Organisational learning is essential to achieving and sustaining change in higher education. Innovative Higher Education, vol. 28, no. 2, pp119-136.

- Chou, S W (2003). Computer systems to facilitating organisational learning: IT and Organisational Context. Expert Systems with Applications, vol. 24, no. 3, pp 2730280.

- Conaway, R N; Easton, S S and Schmidt, W V (2005). Strategies for enhancing student interaction and immediacy in online courses. Business Communication Quarterly, 68, 1, pp23-35.

- Dearing, R (1997). “Higher Education in the Learning Society.” Report to the national Committee of Inquiry into Higher Education, HMSO, Norwich, UK.

- Elkin G (2005). Visualising the Internationalisation of Universities. International Journal of Educational Management, 19, 4.

- Falconer, L (2006). Organisational learning, tacit information and elearning: a review. The Learning Organisation, 13, 2, pp 140-151.

- Fry, H., Ketteridge, S. and Marshall, S. (1999). "Understanding student learning." in A handbook for teaching and learning in higher education by Fry, H., Ketteridge, S. and Marshall, S. (Eds.), London: Kogan Page.

- Gladstone, B (2000). “From Know-How to Knowledge." The Industrial Society, London, UK.

- Goodfellow, R (2004). Key practices in e-learning across the university curriculum. Institute of Educational Technology, Open University. Available at: http://iet.open.ac.uk/pp/r.goodfellow/rome2004/seminar.htm (accessed 21st July 2009)

- Goodfellow, R. (2005). Academic Literacies and e-Learning: a critical approach to writing in the online university, International Journal of Educational Research, 43,7-8: 481-494

- Goodfellow, R (2007). "Rethinking Educational Technologies in the Age of Social Media: from 'tools for interaction' to 'sites of practice'." Keynote for Echanger Pour Apprendre en Ligne conference, Universite Standhal, Grenoble, June. Available at : http://ietstaff.open.ac.uk/r.goodfellow/Presentations2007.htm (accessed 1st July 2009).

- Goodfellow, R. and Lea, M (2007). Challenging e-Learning in the University - a Literacy Approach, McGraw Hill/Open University Press, Studies in Research in Higher Education series

- Goodyear, P and Jones, C (2003). Implicit theories of learning and change: their role in the development of e-learning environments in higher 
education.” In Naidu, S (Ed.), Learning and Teaching with Technology: Principles and Practice, Routledge Farmer, London and New York, NY, pp 29-41.

- Gosper, M; Green, D; McNeill, M; Phillips, R; Preston, G and Woo, K (2008). The impact of web-based lecture technologies on current and future practices in learning and teaching. Available at: www.cpd.mq.edu.au/teaching/wblt/research/report.html (accessed 12th December 2009).

- Hamilton, B A and Scandura, T A (2003). Implications for organisational learning and development in a wired world. Organisational Dynamics, 31, 4, pp 388-402.

- Hannon, J and D’Netto, B (2007). Cultural diversity online: student engagement with learning technologies. International Journal of Educational Management, 21, 5 pp 418-432.

- Institute of Teaching and Learning in Higher Education Conference (2003). University of Central England January.

- Jackson, B. (1998). "Evaluation of learning technology implementation”, in Evaluation studies, N. Mogey (Ed.), pp. 22-25, Learning technology dissemination initiative, Edinburgh.

- Kalkota, R \& Whinston, A B (1996). "Frontiers of Electronic Commerce." Addison Wesley.

- Lanham, E and Zhou, A W (2003). Cultural Issues in online learning - is blended learning a possible solution? International Journal of Computer Processing of Oriental Languages, vol. 16, no. 4, pp 275-92.

- Laurillard, D (2005). Rethinking University Teaching: A Conversational Framework for the effective use of learning technologies. Routledge Falmer, London, UK.

- Laurillard, D (2008). Digital Technologies and their role in achieving our ambitions for education. Institute of Education, University of London, UK.

- Lissenburgh, S (1999). “Knowledge Links.” New Economy, Vol. 6, Issue 1.

- Macfadyen, L P (2005). The culture(s) of cyberspace. In Ghaoui , C (ed), Encyclopaedia of Human-Computer Interaction, The Idea Group Inc., Hershey, PA, pp 143-149.

- Owens, J (2002). "E-Quality: A Knowledge Management (KM) based framework for E-Business-Learning (EBL) at Higher Educational Business Institutes (HEBI). Manufacturing Engineering Journal, Vol. 84, Issue 3. 
- Owens, J D and McManus, J (2004). "E-Business: Knowledge transfer from higher educational institutions to industry.” International Conference on Intellectual Capital, Knowledge Management and Organisational Learning, University of Toronto, Toronto, Canada, 29-30 October.

- Owens, J D (2006). "Electronic Business: A business model can make the difference.” The Management Services Journal, Vol. 50, Issues 1, pp 2429.

- Owens, J D and Floyd, D (2007). "E-Learning as a tool for Knowledge Transfer through traditional and independent study at two UK Higher Educational Institutes: A Case Study.” E-Learning Journal, Vol. 4, no.2.

- Oxford Internet Survey (2005). Oxford Internet Survey 2005 by Oxford Internet Institute (OII). www.oii.ox.ac.uk

- Reeder, K; Macfadyen, L P; Chase, M and Roche, J (2004). Negotiating culture in cyberspace: participation pattern and probelmatics.” Language learning and Technology, vol.8, no. 2, pp88-105.

- Roberts, G (2004). Teaching using the Web: conceptions and approaches from a phenomenographic perspective." Advances in research in networked Learning. Kluwer Academic Publishers, Boston, MA, USA.

- Sims, R and Jones, D (2002). Continuous improvement through shared understanding: reconceptualising instructional design for online learning. Ascilite Conference 2002, Auckland, New Zealand, 8-11 December. Available at: http://ascilite.org.au/conferences/auckland02/proceedingds/papers/162.pdf (accessed $15^{\text {th }}$ June 2009).

- Student Expectations Study (2007). Key findings from online research and discussion evenings held in June 2007 for the Joint Information Systems Committee. Available at: www.jisc.ac.uk/media/documents/publications/studentexpectations.pdf (accessed December $12^{\text {th }}$ 2009)

- Turban, E, Lee, J, King, D \& Chung, H M (2000). "Electronic Commerce: A managerial Perspective.” Prentice-Hall, London, UK.

- Wang, C L and Ahmed, P K (2003). Organisational learning: a critical review. The Learning Organisation, 10, 1, pp 8-17.

- Weller, M (2004). Models of large scale e-learning. JALN, vol. 8, no. 4. 


\section{Author Biographies}

Jonathan D Owens is a Senior Lecturer in Operations and Logistics Management at Lincoln Business School, University of Lincoln, United Kingdom. His research interests are in New Product Development Issues and the appreciation of having a structured technology road map incorporated into the process, the learning issues to be understood in the design process, in particular the NPD process, innovation and design and knowledge transfer through distance learning. He is a Chartered Engineer and currently a Visiting Professor in Logistics Management for the Tecnológico de Monterrey University, México.

Correspondence: Jonathan D Owens, Senior Lecturer in Operations and Logistics Management, Lincoln Business School, University of Lincoln, Brayford Pool, Lincoln. LN6 7TS. UK. jowens@lincoln.ac.uk

Liz Price is a Senior Research Fellow in the Enterprise Research and Development Unit at Lincoln Business School, University of Lincoln. She has undertaken research into small business and innovation policy, broadband and e-commerce, and regional economic development. Liz has managed a number of research projects on behalf of the Learning and Skills Council, Business Link, Lincolnshire County Council, and the European Commission.

Correspondence: Liz Price, Senior Research Fellow, Lincoln Business School, University of Lincoln, Brayford Pool, Lincoln. LN6 7TS. UK. lprice@lincoln.ac.uk 